\title{
PARÂMETROS MORFOLÓGICOS E OS ESCORREGAMENTOS NA BACIA DO RIO GURUTUBA, VALE DO RIBEIRA (SP)
}

\author{
José Eduardo Bonini ${ }^{(a)}$, Bianca Carvalho Vieira ${ }^{(\mathrm{b})}$, Tiago Damas Martins ${ }^{(\mathrm{c})}$, Marcelo Gramani ${ }^{(\mathrm{d})}$ \\ (a) Departamento de Geografia/ FFLCH, Universidade de São Paulo (USP), jose.bonini @usp.br \\ (b) Departamento de Geografia/ FFLCH, Universidade de São Paulo (USP), biancacv@usp.br \\ (c) Departamento de Ciências Geográficas (BFP/FACEPE), Universidade Federal de Pernambuco (UFPE), \\ martins.td@gmail.com \\ (d) Seção de Investigação, Riscos e Desastres Naturais/ Instituto de Pesquisas Tecnológicas de São Paulo, \\ mgramani@ipt.br
}

\section{Eixo: GEOGRAFIA FISSICA E DESASTRES NATURAIS}

\begin{abstract}
Resumo
O presente trabalho traz um estudo realizado para a bacia do Alto Gurutuba, afetada por intensas precipitações em 2014 que desencadearam uma grande quantidade de escorregamentos, resultando no desastre ocorrido no município de Itaóca (SP), onde se localiza a área de estudo. O objetivo foi avaliar a relação entre os escorregamentos deflagrados na bacia e os parâmetros morfológicos de hipsometria, inclinação, aspecto e curvatura das encostas. Foi utilizado um Modelo Digital de Elevação (MDE) para extrair os dados topográficos e indices de Concentração de Cicatrizes para avaliar as classes topograficas mais suscetiveis a escorregamentos rasos.
\end{abstract}

Palavras chave: Vale do Ribeira; Itaóca; Movimentos de Massa; Parâmetros Morfológicos; Concentração de Cicatrizes; Suscetibilidade.

\section{Introdução}

Os movimentos de massa são processos atuantes sobre as encostas, podendo ocorrer de maneira rápida ou lenta, caracterizados pela mobilização de material pela força gravitacional, com ou sem ajuda de água corrente como agente de transporte (CROZIER, 1986, SELBY, 1993). Sua deflagração pode estar relacionada a intensos períodos de precipitação pluvial, condicionando a saturação do solo e com uma superfície de ruptura, a exemplo dos escorregamentos translacionais rasos (SUMMERFIELD, 1991; SELBY, 1993; BIERMAN e MONTGOMERY, 2014).

No Brasil, estes processos são recorrentes nas escarpas da Serra do Mar, especialmente durante o verão, estação do ano que registra altos valores acumulados de precipitação. Em janeiro de 2014 o município de Itaóca, na porção sul do Estado de São Paulo, foram deflagrados escorregamentos rasos e corridas de detritos, sobretudo na bacia hidrográfica do córrego Guarda-Mão, que atingiu o município de Itaóca, gerando grandes prejuízos materiais e perdas de vidas (Figura 1A). Igualmente na bacia do rio Gurutuba, as fortes chuvas deflagraram mais de duas centenas de escorregamentos (Figura 1B). 


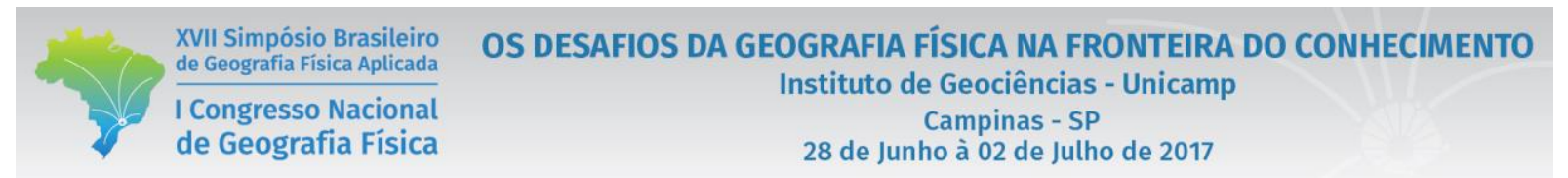

Assim, o objetivo do trabalho foi estabelecer uma relação entre os parâmetros morfológicos da bacia do Alto Gurutuba (hipsometria, aspecto, ângulo de inclinação e curvatura das encostas) e os escorregamentos ocorridos no evento de 2014.

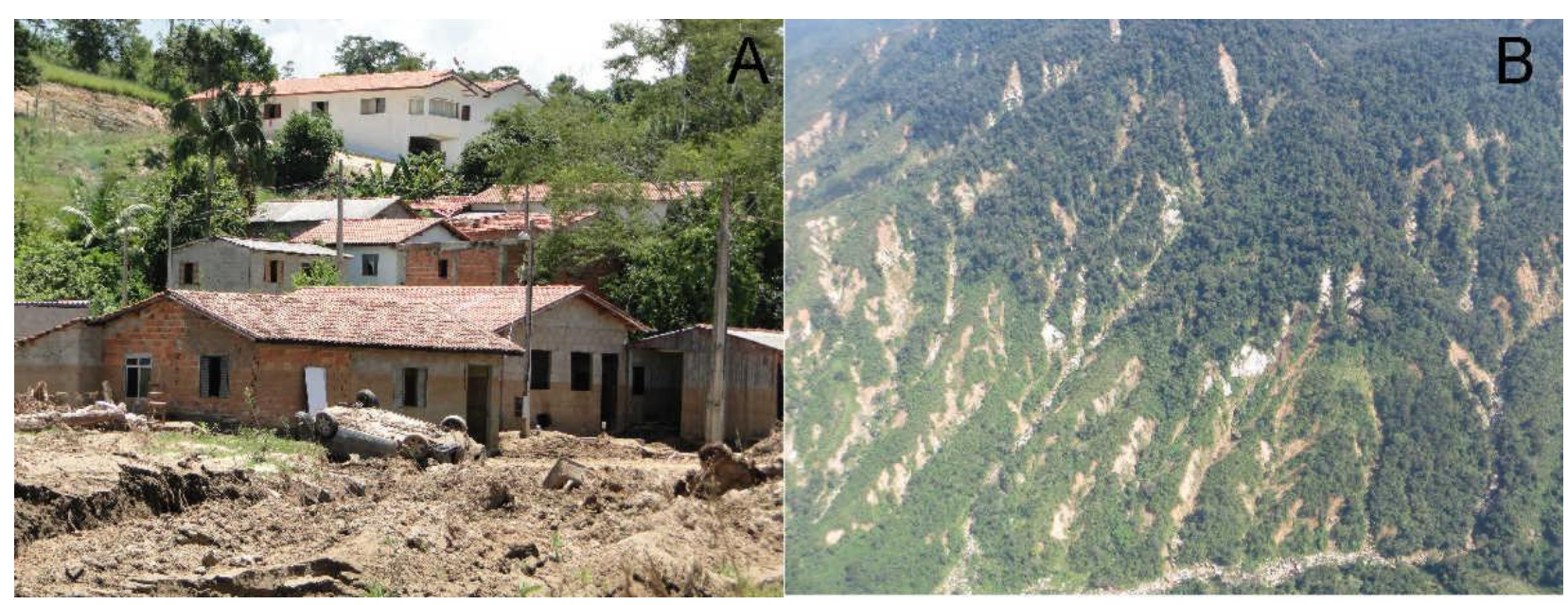

Figura 1 (A) Vista de parte do município de Itaóca afetada pela corrida de detritos da bacia do rio Guarda-Mão. (B)

Fotos oblíquas das cicatrizes dos escorregamentos da bacia do Alto Gurutuba. Fonte das Fotos: Marcelo Gramani

\section{2. Área de Estudo}

A área de estudo, bacia do rio Alto Gurutuba, localiza-se no município de Itaóca (SP), divisa com o Estado do Paraná (Figura 2), integrando a Unidade de Gerenciamento de Recursos Hídricos 11 - Ribeira do Iguape (UGRHI 11), sub-bacia do Baixo Ribeira e afluente do Rio Palmital. O município apresenta um histórico de ocorrências de processos como inundações, escorregamentos e, recentemente, corridas de detritos, tendo condições fisiográficas favoráveis ao desencadeamento destes (Brollo et al.,2015).

A bacia do Alto Gurutuba possui aproximadamente $4,56 \mathrm{~km}^{2}$ de área, sendo selecionada para este estudo devido aos escorregamentos bastante concentrados deflagrados entre os dias 13 e 14 de janeiro de 2014, desencadeados por chuvas intensas num curto período de tempo focadas nas cabeceiras de drenagem de afluentes do rio Palmital (BROLLO et al., 2015; GRAMANI, 2015; GRAMANI e ARDUIN, 2015). 

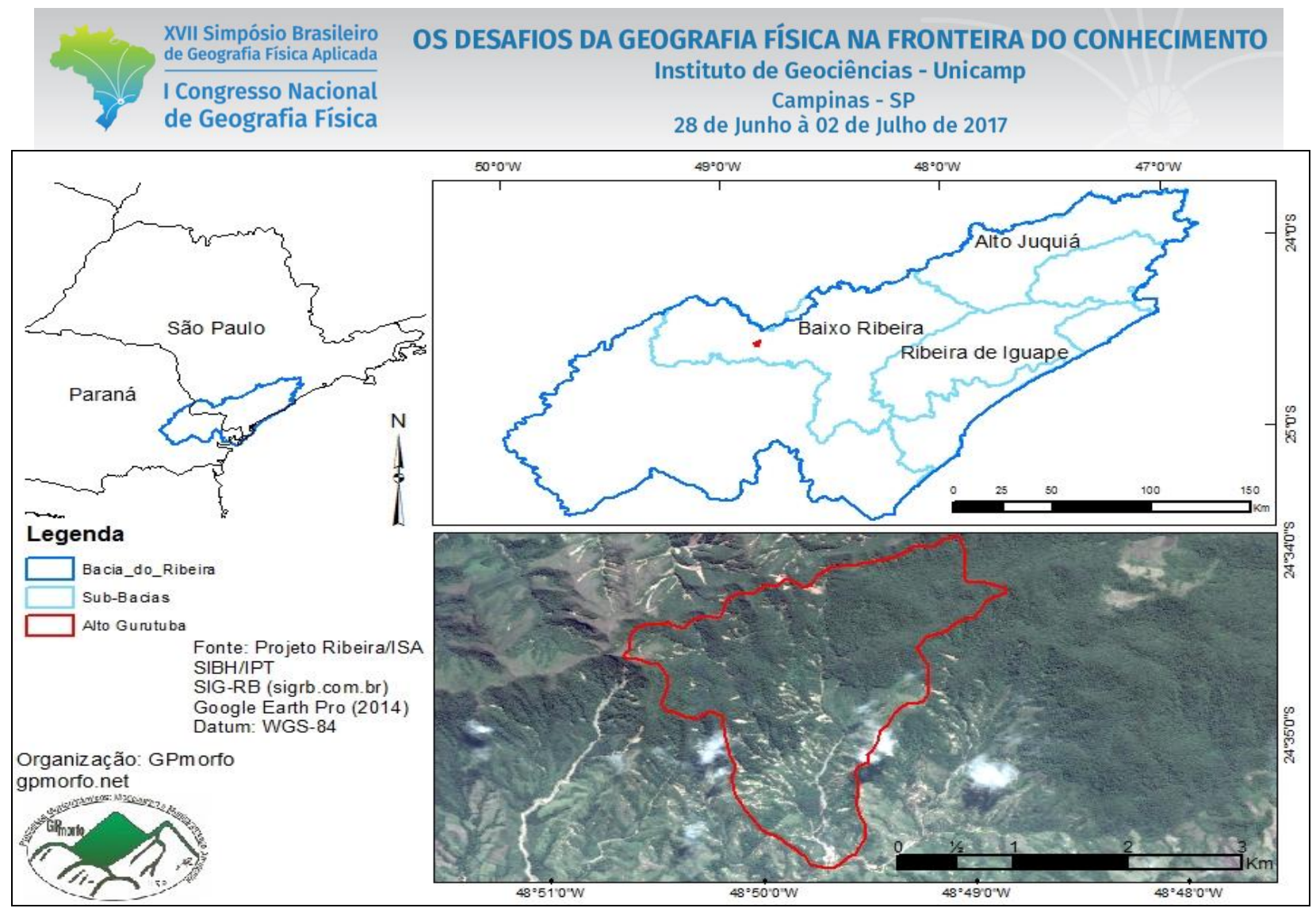

Figura 2 - Localização da bacia do Ribeira no Estado de São Paulo e suas principais sub-bacias. A Bacia do Alto Gurutuba se localiza na chamada sub-bacia do Baixo Ribeira. É possível notar na imagem as cicatrizes dos escorregamentos de 2014.

Do ponto de vista da geologia, a bacia se insere na Unidade Itaóca, que ocupa cerca de $70 \%$ da área do Batólito Itaóca - composto de granitóides calcioalcalinos monzoníticos, parte do Cinturão de Dobramentos do Ribeira, com rochas encaixantes do subgrupo Lajeado (MELLO E BETTENCOURT, 1998; FALEIROS et al., 2012). A drenagem e as encostas da área, devido à proximidade das Zonas de Cisalhamento Ribeira e Figueira (FALEIROS et. al, 2012), apresentam indícios de controle estrutural, como cotovelos e faces triangulares, respectivamente.

Ross (2002) aponta que a bacia do Ribeira do Iguape apresenta relevos alongados, topos convexos e vales predominantemente estreitos e profundos, com encostas de inclinações entre 30\% e 60\%. Brollo et. al. (2015), ao caracterizar o município de Itaóca, indicam que os setores côncavos do relevo onde o Granito Itaóca é o substrato geológico apresentam espesso manto de alteração argilo-siltico-arenoso, o que nos fornece uma primeira aproximação acerca da natureza dos solos da região.

\section{Materiais e Métodos}


Para alcançar o objetivo deste trabalho primeiramente foram vetorizadas duas cartas topográficas (Folhas Ribeirão das Pedras e Rio Palmital), em escala 1: 10.000 adquiridas no Instituto Geográfico e Cartográfico (IGC). Posteriormente, utilizando a ferramenta Topo to Raster (Arcgis 10.3), foi elaborado um Modelo Digital de Elevação (MDE) com resolução de 10m. Com o MDE foram criados os mapas de hipsometria, aspecto, declividade e curvatura das encostas, utilizando o mesmo software.

Para caracterizar a morfologia da bacia, foi calculada a Frequência $(F)$ de cada parâmetro, que consiste na razão entre o número de células de cada classe (ex: a classe hipsométrica < 350m possui 3.364 células) e o total de células da bacia (45.638). O mapa de cicatrizes utilizado neste trabalho foi elaborado por Carou et. al. (2017), sendo sobreposto aos mapas temáticos de hipsometria, aspecto, curvatura e inclinação da encosta e, a partir disto, calculamos o índice de Concentração de Cicatrizes (CC), obtido por meio da divisão do total de células que apresentaram cicatrizes em cada classe pelo total da bacia.

\section{Resultados e Discussão}

Primeiramente, a análise da hipsometria (Figura 3A) mostrou que 30,4\% da área da bacia se encontram entre 750 e $850 \mathrm{~m}$, com as áreas mais elevadas próximas ao interflúvio norte com classes acima de 950m de altitude. Quando avaliado o índice CC, verificou-se que cerca de $23 \%$ das cicatrizes se concentraram na classe entre $850-950 \mathrm{~m}$, seguida pela classe $450-550 \mathrm{~m}$, que concentrou quase $21 \%$ dos escorregamentos (Figura 4A). Entretanto, é importante destacar que esta última perfaz apenas $9 \%$ da bacia podendo indicar sua maior suscetibilidade. Lan et. al. (2004) apontam que este parâmetro, quando analisado isoladamente, não é capaz de explicar a concentração de cicatrizes, sendo mais explicativo quando abordado juntamente com os demais parâmetros.

Quanto ao mapa de aspecto (Figura 3B), observa-se que a bacia possui a maior parte de suas encostas com orientação para Sul (20,8\%), Sudeste (20,8\%), e Leste (18,2\%) (Figura 4B), sendo estas duas também mais afetadas pelos escorregamentos: Leste $(37,2 \%)$ e Sudeste $(29,4 \%)$. Já as encostas menos afetadas foram: Norte (1,6\%) e Noroeste (1,7\%). Nery e Vieira (2015), estudando a Serra do Mar paulista, especificamente a bacia do Ultrafértil, também encontraram uma maior concentração de cicatrizes nas encostas orientadas para Leste. Lin et.al. (2016), trabalhando na bacia do rio Gurutuba (SP), também encontraram uma maior concentração de cicatrizes nas encostas voltadas para Leste e Sudeste.

Referente ao mapa de ângulo das encostas (Figuras 3C e 4C), 24,4\% da área da bacia possui encostas entre $25^{\circ}$ e $30^{\circ}$, tendo apenas $12,6 \%$ de encostas menos íngremes $\left(<15^{\circ}\right)$. O índice CC mostrou uma tendência de aumento de escorregamentos a partir da classe de $20^{\circ}-25^{\circ}$, atingindo um máximo na classe de $30^{\circ}-35^{\circ}(26,5 \%)$ e declinando a partir disso. Tal comportamento foi semelhante aos resultados obtidos por 
Fernandes et al. (2004) para as bacias dos rios Quitite e Papagaio (RJ); Kamp et al. (2008) em seus estudos sobre a região da Caxemira (Paquistão); Nery e Vieira (2014) e Lin et al (2016).

Por fim, o último parâmetro analisado foi o de curvatura das encostas (Figura 4D), sendo observável uma Frequência equilibrada entre as três classes (Convexo - 33,3\% ; Retilíneo - 34,9\%; e Côncavo - 31,8\%). Também o índice CC apresentou valores próximos para cada classe, indicando maior suscetibilidade nas encostas Convexas (35,2\%) e Côncavas (33,9\%). Dietrich e Montgomery (1994) apontam que as porções côncavas do relevo são mais suscetíveis a ocorrência de escorregamentos, devido à convergência de fluxos para estas áreas. Consequentemente, era esperado que os maiores valores de $\mathrm{CC}$ se encontrassem nesta classe, como ocorre em outros trabalhos, a exemplo de Fernandes et al. (2004). 

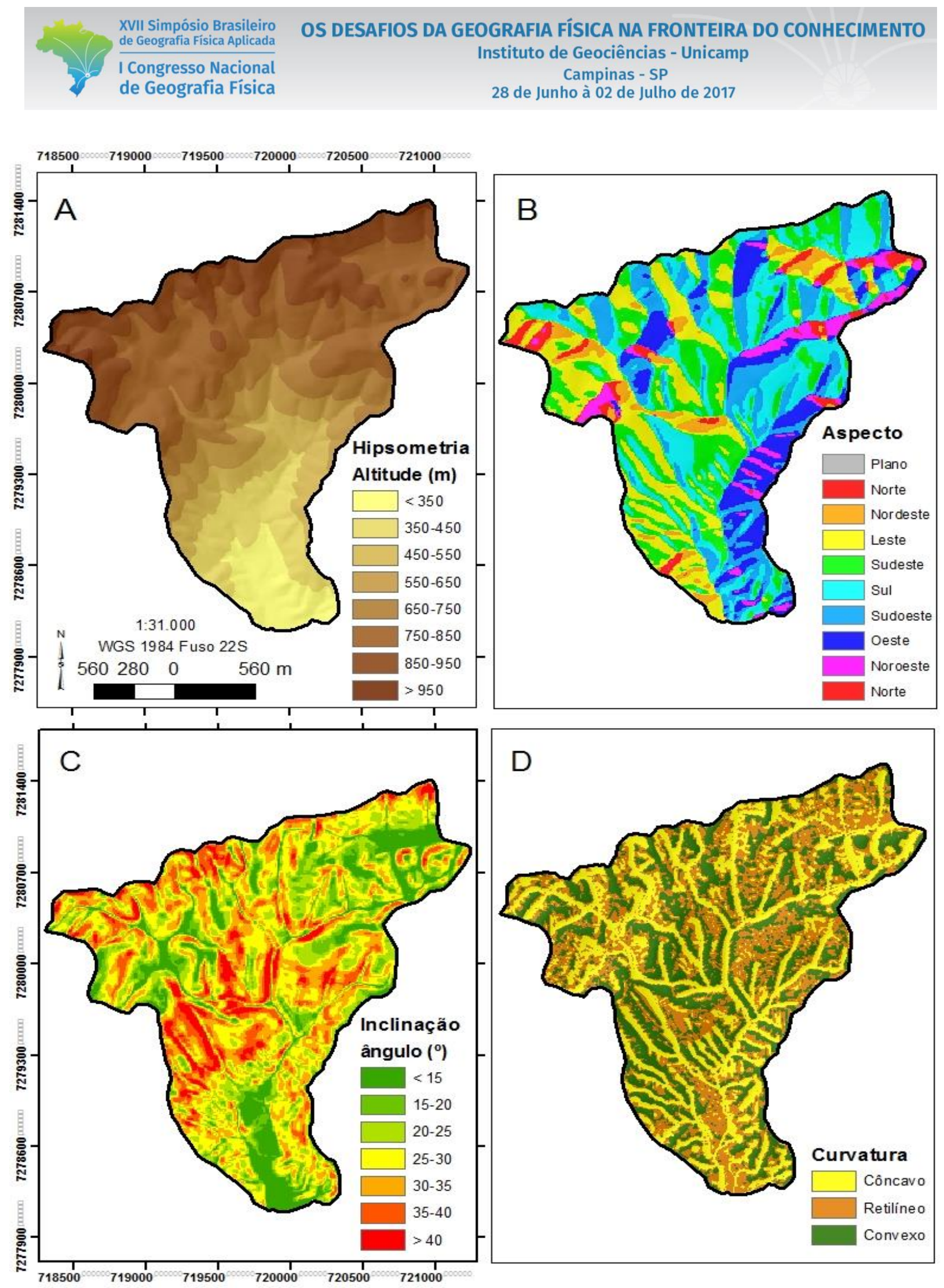

Figura 3 - Mapas dos parâmetros morfológicos hipsometria (A), aspecto (B), ângulo das encostas (C) e curvatura das encostas (D). 
XVII Simpósio Brasileiro de Geografia Fisica Aplicada

I Congresso Nacional de Geografia Física
OS DESAFIOS DA GEOGRAFIA FÍSICA NA FRONTEIRA DO CONHECIMENTO

Instituto de Geociências - Unicamp

Campinas - SP

28 de Junho à 02 de Julho de 2017

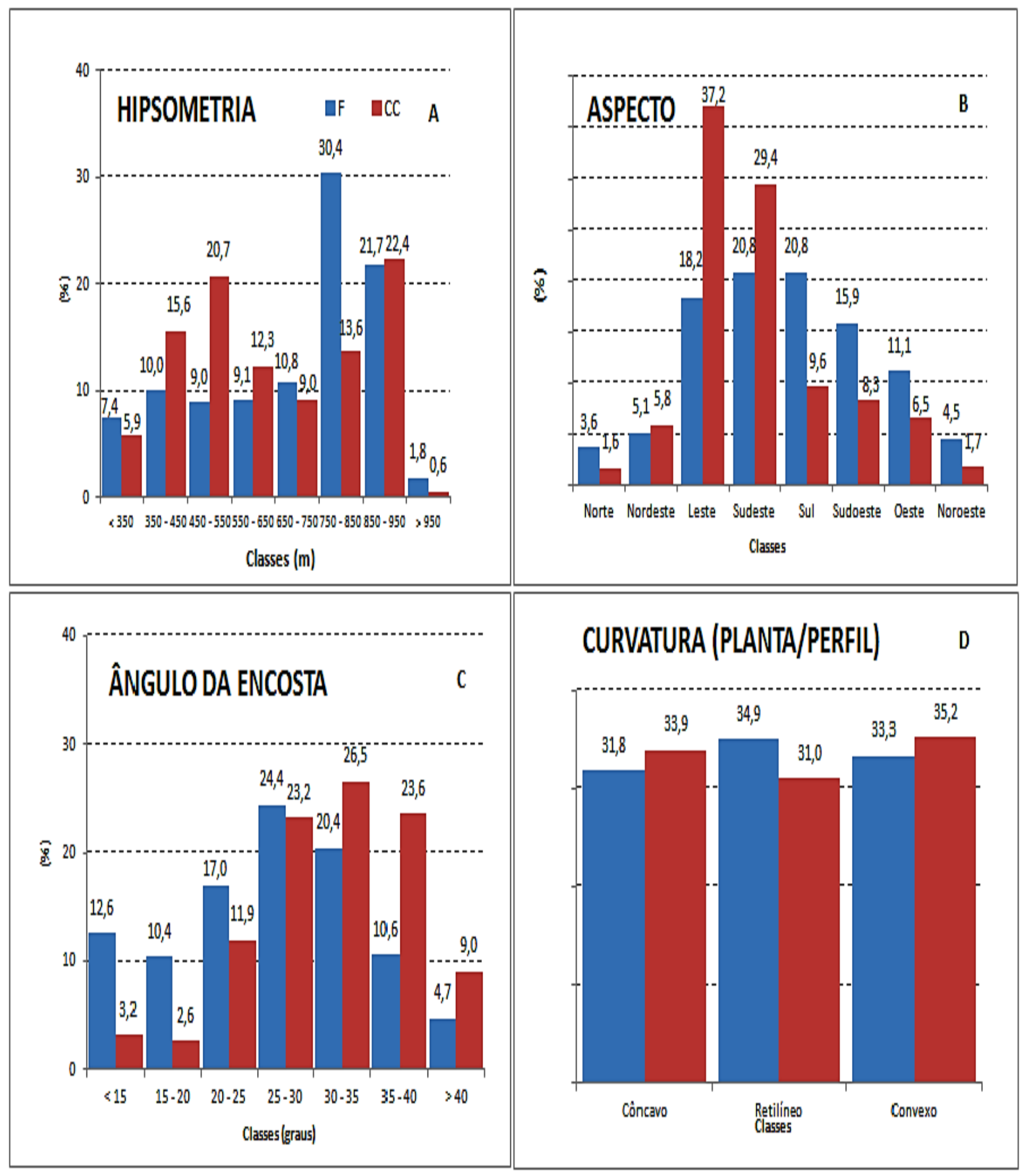

Figura 4 - Frequência e Concentração de Cicatrizes para os parâmetros morfológicos hipsometria (A), aspecto (B), ângulo das encostas (C) e curvatura (D). 
A leitura conjunta dos mapas de ângulo e de curvatura revela uma grande concentração de encostas convexas com ângulos de inclinação entre 25 e $40^{\circ}$, que concentraram mais de $73 \%$ dos escorregamentos. Já a avaliação dos mapas hipsométrico e de curvatura nos mostra que uma grande parte das áreas convexas coincide com altitudes entre os 450 e 750m, intervalo que apresentou um CC de 42\%. Finalmente, há uma grande incidência das encostas voltadas para leste e sudeste na mesma porção onde as áreas convexas se concentram no mapa, sendo que as encostas com esta orientação somam um CC de 66,6\%.

\section{Conclusões}

Por meio da análise dos mapas temáticos e dos índices de Frequência (F) e Concentração de Cicatrizes (CC), foi possível indicar as classes mais suscetíveis de cada um dos parâmetros morfológicos à ocorrência de escorregamentos na bacia do Alto Gurutuba.

Futuros trabalhos nesta área poderão incluir outras variáveis na análise, como a litologia e solos, além de ser possível produzir um mapa de suscetibilidade aos escorregamentos e corridas, que poderão contribuir para o planejamento dos municípios afetados pelo evento de 2014.

\section{Agradecimentos}

Os autores agradecem a Fundação de Amparo à Pesquisa do Estado de São Paulo (FAPESP) pelo financiamento desta pesquisa (Processo n ${ }^{\circ}$ 2016/20363-9), ainda em etapa inicial.

\section{Bibliografia}

BIERMAN, P.R. \& MONTGOMERY, D.R. 2014. Hillslope. In: Key Concepts in Geomorphology. W.H. Freeman and Company Publishers New York. 145-178.

BROLLO, M. J.; SANTORO, J.; PENTEADO, D. R.; FERNANDES AD SILVA, P. C.; RIBEIRO, R. R.. Itaoca (SP): Histórico de acidentes e desastres relacionados a perigos geológicos. $14^{\circ}$ Simpósio de Geologia do Sudeste. Campos do Jordão - SP, 2015.

CAROU, C. B.; VIERA, B. C.; MARTINS, T. D.; GRAMANI, M. F.. 2017. Inventário dos escorregamentos da Bacia do rio Gurutuba, Vale do Ribeira (SP). Simpósio Brasileiro de Geografia Física Aplicada - XVII SBGFA, Campinas, São Paulo, Brasil (no prelo).

CROZIER, M. J. Landslides: causes, consequences and environment. New Zeland. 1986.

FALEIROS, F. M. et. al. Geologia e recursos minerais da Folha Apiaí - SG.22-X-B-V, Estados de São Paulo e Paraná, Escala 1:100.000 - São Paulo: CPRM, 107 P. 2012. 


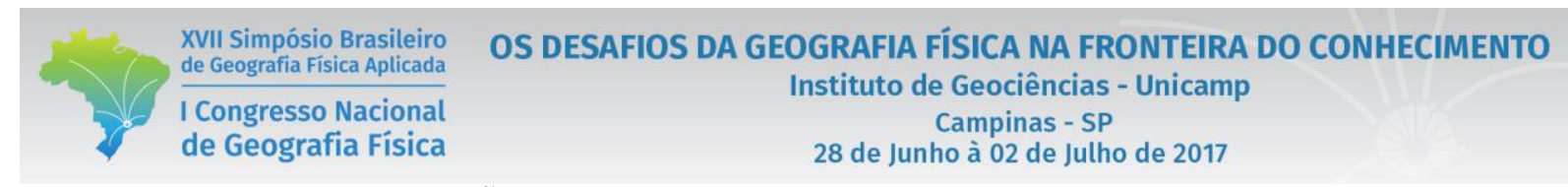

FERNANDES, N. F.; GUIMARÃES, R. F.; GOMES, R.A.T.; VIEIRA, B. C.; MONTGOMERY, D. R.; GREENBERG, H. Topographic controls of landslides in Rio de Janeiro: Field evidence and modeling. CATENA, 55, 163-181, 2004.

GAO, J. Identification of Topographic Settings Conductive to Landsliding From Nelson County, Virginia, U.S.A. Earth Surface Processes and Landforms: 579-591, 1993.

GRAMANI, M. F. A corrida de massa no Córrego Guarda-Mão, Município de Itaóca (SP): Impacto e Observações de Campo. $15^{\circ}$ Congresso Brasileiro de Geologia de Engenharia e Ambiental. Bento Gonçalves - RS, 2015.

GRAMANI, M. F.; ARDUIN, D. H. Morfologia da drenagem dos depósitos de debris flow em Itaoca, São Paulo. $15^{\circ}$ Congresso Brasileiro de Geologia de Engenharia e Ambiental. Bento Gonçalves - RS, 2015.

KAMP, U; GROWLEY, B. J.; KHATTAK., G. A.; OWEN, L. A. GIS-based landslide susceptibility mapping for the 2005 Kashmir earthquake region. Geomorphology (101): 631-642, 2008.

LAN, H. X.; ZHOU, C. H.; WANG, L. J.; ZHANG, H. Y.; LI, R. H. Landslide hazard spatial analysis and prediction using GIS in the Xiaojiang watershed, Yunnan, China. Engineering Geology (76): 109-128, 2004.

LIN, C.C.; GRAMANI, M.F.; CAMPOS, A. B. Levantamento das cicatrizes de deslizamentos na bacia do Rio Gurutuba (SP) e correlações com parâmetros físicos. XVIII Congresso Brasileiro de Mecânica dos Solos e Engenharia Geotécnica. Belo Horizonte - MG, 2016.

MELLO, I.S.C.; BETTENCOURT, J.S. Geologia e Gênese das Mineralizações associadas ao Maciço Itaoca, Vale do Ribeira, SP e PR. Revista Brasileira de Geociências 28(3):269-284, 1998.

NERY, T. D.; VIEIRA, B.C. Susceptibility to shallow landslides in a drainage basin in the Serra do Mar, São Paulo, Brazil, predicted using the SINMAP mathematical model. Bull. Eng. Geol. Environ, 74, 369-378, 2015.

ROSS, J.L.S. A morfogênese da bacia do Ribeira do Iguape e os Sistemas Ambientais. GEOUSP - Espaço e Tempo, São Paulo, no 12, p. 21-46, 2002.

SELBY, M. J. Hillslope: materials \& processes. New York. 1993.

SUMMERFIELD, M.A. Global Geomorphology: an introduction to the study of Landforms. New York, Longman Scientific e Technical and John Wiley e Sons Inc., 537p, 1991. 